\title{
Review
}

Martin Rhême*, John Botsis, Joël Cugnoni and Parviz Navi

\section{Influence of the moisture content on the fracture characteristics of welded wood joint. Part 1: Mode I fracture}

\begin{abstract}
Friction welding is a joining technique for wood materials. The positive aspects of this technique are the speed of processing and the absence of chemical or mechanical agents, but the welded joints are not water resistant. To understand better the effect of moisture on the fracture behavior of welded joints, their fracture characteristics have been investigated. The double cantilever beam specimens were tested, which permit to compute the mode I energy release rate of a welded joint. The results confirm the negative effect of moisture on the fracture properties of the joint. The data concerning the maximal tensile strength of the joining material were collected by uniaxial tests and implemented in a finite element model to establish a cohesive law, which describes the behavior of welded pieces in terms of moisture content.
\end{abstract}

Keywords: beech (Fagus sylvatica), cohesive law, FEM, fracture mechanics, friction welding, moisture content

*Corresponding author: Martin Rhême, Material and Wood Technologies, Bern University of Applied Science, Bienne, Switzerland, e-mail: martin.rheme@bfh.ch John Botsis and Joël Cugnoni: Laboratory of Applied Mechanics and Reliability Analysis, EPFL, Lausanne, Switzerland

Parviz Navi: Material and Wood Technologies, Bern University of Applied Science, Bienne, Switzerland

\section{Introduction}

Assembling wood pieces is the most essential basis of mechanical wood technology. There are many different natural and synthetic adhesives developed to each special task and there is a good solution for nearly all adhesive problems of wood (Dunky and Niemz 2002). However, the synthetic glues give some ecological concern; moreover, they need a certain time for drying or curing. The recycling of glued wood is aggravated.

The welding of wood is an alternate process under development, which connects two wood pieces by the heat developed during friction without any adhesive. The adhesion is generated in the interface from the thin layer of molten wood substances after solidification (Gfeller et al. 2003). The mechanical performance of the process is frequently investigated by varying the parameters, such as welding time and pressure, amplitude of vibration, and surface quality, and by submitting the welded specimens to shear test according to DIN-EN (2003) 205 (Gfeller et al. 2003, 2004; Ganne-Chédeville et al. 2005; Ganne-Chédeville 2008). Ganne-Chédeville et al. (2008) observed the behavior of double cantilever beam (DCB) specimens and measured the critical energy release rate $\left(\mathrm{G}_{\mathrm{I}}\right)$ of a welded joint. The results were in the range of data of conventional adhesives. Omrani et al. (2009) focused on the specimens jointed with a $150 \mathrm{~Hz}$ frequency welding and studied the influence of fiber orientation and wood species on the value of $\mathrm{G}_{\mathrm{Ic}}$. Ganne-Chédeville (2008) demonstrated that the shear resistance of welded joints drops drastically after $3 \mathrm{~h}$ of water immersion. Mansouri et al. (2009) succeeded to improve moderately the water resistance of wood joints by higher welding frequency. Vaziri et al. (2010) monitored the evolution of the crack length of welded specimen during water absorption by X-ray computed tomography. However, the effects of the moisture on the mechanical properties have not yet been quantified.

There are overviews concerning the fracture properties of wood (Navi and Stanzl-Tschegg 2009; StanzlTschegg and Navi 2009). During crack propagation, the softening behavior is reported and fiber bridging occurs behind the crack tip. Like the other mechanical properties of wood, the fracture characteristics are also influenced by moisture, that is, they tend to decrease with increasing moisture content (MC) (Pluvinage 1992; Vasic and Stanzl-Tschegg 2007; Majano-Majano et al. 2012). The maximal value of the stress intensity factor (i.e., fracture toughness $\mathrm{K}_{\mathrm{IC}}$ ) is reached at $16 \% \mathrm{MC}$ (Liyu et al. 2003) or between 7\% and 13\% MC (Kretschmann and Green 1996). Prokopski (1996) even found an opposite trend of $\mathrm{K}_{\mathrm{Ic}}$ with $\mathrm{MC}$ of oak and pine (species not more accurately defined by the authors). Obviously, the 
correlation between MC and crack resistance is not clear in all details.

The mode I fracture (i.e., opening mode) of glued wood with the DCB specimens is frequently applied due to its simplicity in processing (Duchanois 1984; Wernersson 1991; Gagliano and Frazier 2001; Conrad et al. 2003; Frühmann et al. 2003; Yoshihara 2010). Some authors have selected the tapered version of the DCB specimens (Scott et al. 1992; Simon 2001; Qiao et al. 2003) to obtain a linear variation of the compliance with the crack length and to have less scattering results.

The present work is aiming at a better understanding of the behavior of welded wood assemblies in the presence of moisture. The experimental and numerical studies will be presented in two articles in terms of the fracture characteristics of the welded joint as a function of MC. The focus of the first article is on the mode I loading of DCB specimens with defined equilibrium MC (EMC), which should be tested according to an ASTM (2007) standard (D5528-01). The fracture mechanical experiments should be performed accompanied by the optical and electron microscopic observations and numerical simulations. Finite element modeling (FEM) should be used to construct a model based on cohesive elements. FEM is a powerful tool to model the failure and interface fracture mechanisms in wood-based materials (Smith et al. 2007; Landis and Navi 2009). The parameters of the cohesive law will be experimentally established with the help of DCB and uniaxial tensile tests. The mode II fracture (i.e., in plane sliding mode) is addressed in part 2 (Rhême et al. 2013).

\section{Materials and methods}

\section{Specimen preparation}

The fracture behavior of the joints will be studied on DCB specimens and the stress-strain response of the joining material on tensile specimens.

\section{DCB specimens}

Beech (Fagus sylvatica) wood beams were machined out of the same plank, which was stored in a climatic chamber $\left[20^{\circ} \mathrm{C} / 65 \%\right.$ relative humidity $(\mathrm{RH})]$. At $\mathrm{EMC}$, beams with dimensions of $300 \times 30 \times 5 \mathrm{~mm}^{3}$ (for the $\mathrm{L}, \mathrm{R}$, and $\mathrm{T}$ directions, respectively) were prepared with a planning machine. For welding, see the next paragraph. To introduce an initial crack in the weld, grease is applied on the pre-crack surfaces to avoid friction and thus welding during the process. The final geometry of the specimen, designed according to the ASTM (2007) standard (D5528-01), is shown in Figure 1a. Four groups of five samples each were placed into four climatic boxes with different RH. The following saturated salt solutions were used: potassium acetate (RH 22\%), sodium nitride ( $\mathrm{RH} 65 \%$ ), potassium chloride (RH 85\%), and ammonium dihydrogen phosphate (RH 93\%). The exact MC was determined on parallel specimens by the oven drying method (DIN (1977) 52-183). The following four MC levels were considered: $6.4 \%, 12.0 \%, 16.2 \%$, and $22.0 \%$. Once EMC is reached, the dimensions of the specimens were measured and their lateral surfaces were covered with a white brittle paint and vertical thin lines were drawn every millimeter to help track crack propagation during testing. Lastly, aluminum blocks with a through hole were glued on the extremities of the beams to serve as load application pins.

a

b
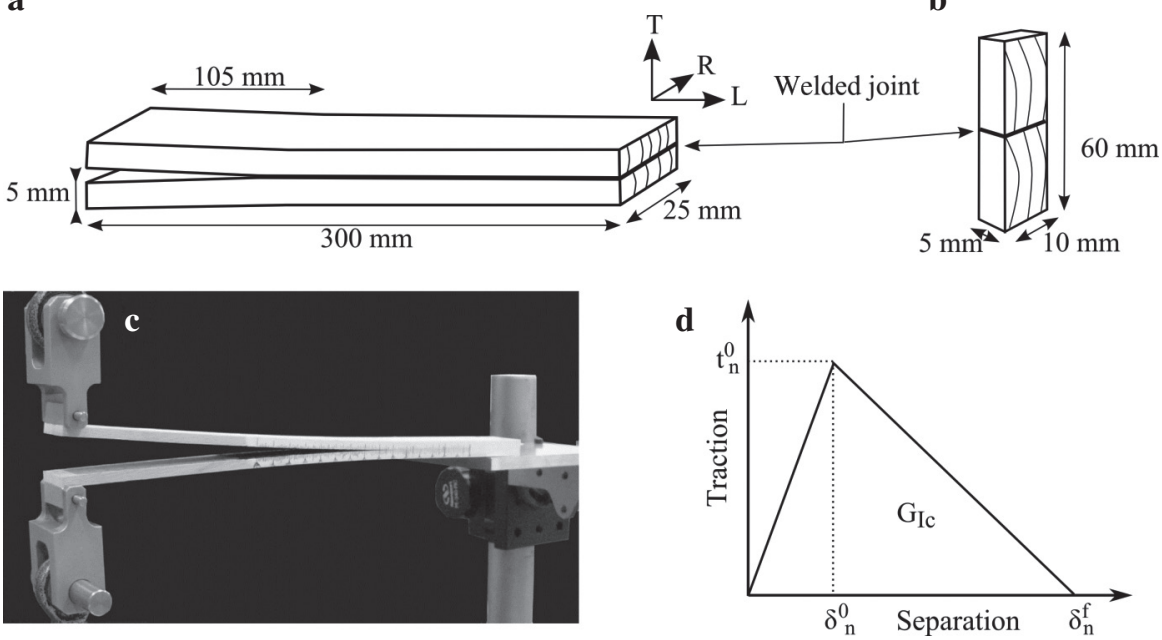

Figure 1 (a) DCB specimen before the gluing of the aluminum blocks. (b) Tensile specimen. For both types of specimen, the tangential direction is perpendicular to the weld plan. (c) Photograph of the DCB specimen in the testing machine. The upper beam is pulled by a constant displacement speed through an articulated fixture (left). A video camera records the pictures of the lateral surface for subsequent measurement of the crack length (see text for details). (d) Traction separation law for the cohesive elements. The maximal traction values $\left(t_{n}{ }^{0}\right)$ at damage initiation are determined by the uniaxial traction tests. Note that the area under the curve is equal to the value of the critical energy release rate $\left(G_{\mathrm{lc}}\right)$ determined by $\mathrm{DCB}$ fracture test. 


\section{Tensile specimens}

The initial wood parts to be welded have the dimensions of $500 \times 20 \times 30 \mathrm{~mm}^{3}$ (for L, R, and T directions, respectively). The welding occurs on the surface of $500 \times 20 \mathrm{~mm}^{2}$. Half of the welded piece served as uniaxial tensile specimens and the other one as torsion specimens described in Part 2 of this work (Rhême et al. 2013). The thickness was reduced by planning to $10 \mathrm{~mm}$, and $5 \mathrm{~mm}$ slices were cut with a circular saw. The surface normal to the longitudinal direction was polished with 240 and $800 \mathrm{SiC}$ paper, which lets the cellular structure of the wood appear. This was necessary for digital image correlation (DIC) studies for surface displacement measurements. The conditions for obtaining the specimens EMC were the same as described above. A total of eight specimens were tested per condition.

\section{Welding process}

Both DCB and tensile specimens were frictionally welded by a Branson M-DT24L linear welding machine. The parameters of the friction step are as follows: time $2.4 \mathrm{~s}$, pressure $1.5 \mathrm{MPa}$, and amplitude $3 \mathrm{~mm}$. The parameters of the holding step are as follows: time $7 \mathrm{~s}$ and pressure 1.5 MPa. More information concerning linear welding and the orbital process is given by Ganne-Chédeville (2008) and Stamm (2005), respectively.

\section{Experimental methods}

\section{Fracture testing}

The DCB specimens were tested on a uniaxial testing machine (Instron 5848 Microtester; Instron, Norwood, MA, USA) with a $2 \mathrm{kN}$ load cell and constant pulling rate of $2 \mathrm{~mm} \mathrm{~min}^{-1}$ (see Figure 1c for details). The pictures were taken of the lateral marked surface at regular time intervals during the test with the help of a camera Guppy from Allied Vision Technologies (Stadtroda, Germany) equipped with a $50 \mathrm{~mm}$ lens. During the test, the load, displacement, and photographs of the advancing crack tips were recorded and stored for evaluation. The mass was measured after removing the specimens from the box, because small variation of the specimen's MC may occur. The MC loss during test was very small and its effects are negligible. After fracture, the profiles of the fractured surface were measured by optical noncontact profilometry. The fracture paths were used to measure the roughness parameters $\left(\mathrm{R}_{\mathrm{a}}\right.$ and $\left.\mathrm{W}_{\mathrm{t}}\right)$ and their fractal dimension was determined by the box counting method.

\section{Tensile testing}

A uniaxial machine was available with a climatic chamber with stable RH and temperature conditions controlled by appropriate sensors. A glass window adapted on the chamber enables to take pictures of the polished surface (perpendicular to the loading direction) during the test. Right before starting the test, the specimen is clamped in the fixture and the chamber is closed followed by a waiting time of $\sim 5 \mathrm{~min}$ for stabilization of the temperature and $\mathrm{RH}$. The specimen is pulled to failure at a displacement rate of $0.33 \mathrm{~mm}$ $\mathrm{min}^{-1}$. After the test, the mass and dimensions of each sample were measured. The natural structure of wood easily enables to measure surface displacements and deduce the strains by DIC by means of the photographs taken.

\section{Finite element modeling}

A two-dimensional FEM to simulate the crack propagation in the DCB specimen was constructed with the help of the software Abaqus/CAE. The beams are represented with quadrilateral plane strain elements and the elastic properties for beech. The variation of the properties of the wood with the MC was taken into account through the following relations of Dinwoodie (1989):

$$
\begin{aligned}
& \mathrm{E}_{\mathrm{d}}=\mathrm{E}_{\text {ref }}\left[1+0.015\left(\mathrm{u}_{\mathrm{ref}}-\mathrm{u}\right)\right] \\
& \mathrm{G}_{\mathrm{d}}=\mathrm{G}_{\text {ref }}\left[1+0.025\left(\mathrm{u}_{\text {ref }}-\mathrm{u}\right)\right] .
\end{aligned}
$$

Subscript $d$ indicates the direction of the property $(\mathrm{L}, \mathrm{R}$, or $\mathrm{T})$ and $\mathrm{E}_{\mathrm{ref}}$ and $\mathrm{G}_{\text {ref }}$ are the moduli at a reference $\mathrm{MC} \mathrm{u}_{\text {ref }}$ (here, $12 \% \mathrm{MC}$ ). The values of the elastic properties are found in the literature (Kollmann 1982; Niemz 1993) and are presented in Table 1. According to the results of Hering et al. (2012), the MC seems to have a little effect on the Poisson's ratios and they will consequently be considered to be constant in this work.

The joint is represented by a layer of cohesive elements governed by a traction separation behavior with linear damage evolution (Figure 1d). These elements have first a linear elastic behavior determined by a stiffness $\mathrm{K}$ followed by damage initiation when a maximal stress criterion is reached:

$$
\operatorname{Max}\left\{\frac{\left\langle t_{n}\right\rangle}{t_{n}^{0}}, \frac{t_{s}}{t_{s}^{0}}, \frac{t_{t}}{t_{t}^{0}}\right\}=1 .
$$

Subscripts $\mathrm{n}, \mathrm{s}$, and $\mathrm{t}$ stand for the direction of the nominal stresses when the deformation is purely normal to the interface (mode I) and purely in the first (mode II) and second (mode III) shear directions s, respectively. The Macaulay brackets indicate that no damage is initiated by the pure compressive stresses (Abaqus 2009). The different peak values $\left(\mathrm{t}_{\mathrm{n}}{ }^{0}, \mathrm{t}_{\mathrm{s}}{ }^{0}\right.$, and $\left.\mathrm{t}_{\mathrm{t}}{ }^{0}\right)$ are material properties and are determined by the experimental tests.

In this article, only pure mode I is addressed. Therefore, only the normal stress $t_{n}{ }^{0}$ is of interest and determined from the data of the tensile test presented in Table 2. The peak value for the shear stresses

Table 1 Reference values of the elastic properties used in the FEM.

\begin{tabular}{lrrr}
\hline Direction & \multicolumn{2}{c}{ Property (GPa) } \\
\cline { 2 - 4 } & $\mathrm{E}_{\mathrm{ref}}$ & $\mathbf{G}_{\text {ref }}$ & $\mathbf{v}$ \\
\hline $\mathrm{L}$ & 14.00 & & \\
$\mathrm{~T}$ & 1.16 & & \\
$\mathrm{R}$ & 2.28 & & \\
LT & & 1.08 & 0.53 \\
LR & & 1.64 & 0.45 \\
RT & & 0.47 & 0.71 \\
\hline
\end{tabular}


Table 2 Values of maximal tensile strength and critical energy release rate measured during this work and used in the cohesive law [Equation (3)] and the corresponding MCs.

\begin{tabular}{lrrrr}
\hline Properties & \multicolumn{3}{c}{ Data at various MC } \\
\cline { 2 - 5 } & $\mathbf{6 . 4 \%}$ & $\mathbf{1 2 . 0 \%}$ & $\mathbf{1 6 . 2 \%}$ & $\mathbf{2 2 . 0 \%}$ \\
\hline $\mathrm{t}_{\mathrm{n}}{ }^{0}[\mathrm{MPa}]$ & 2.7 & 2.7 & 1.9 & 1.0 \\
$\mathrm{G}_{\mathrm{lc}} \frac{\mathrm{J}}{\left[\mathrm{m}^{2}\right]}$ & 72 & 78 & 72 & 37 \\
\hline
\end{tabular}

$\mathrm{t}_{\mathrm{s}}^{0}$ and $\mathrm{t}_{\mathrm{t}}^{0}$ are established according to the results of the torsion tests presented in Part 2 (Rhême et al. 2013). The joining material is very thin in comparison with the specimen's thickness; thus, it does not contribute to the global elastic loading during the DCB test. However, in the numerical simulation, the elastic stiffness of the cohesive elements cannot be infinite. In this work, it is assumed that the separation value at which damage initiates $\left(\delta_{n}{ }^{0}\right)$ is equal to a 10th of the maximal separation $\left(\delta_{n}^{\mathrm{f}}\right)$. Thus, the stiffness of the cohesive element is calculated using Equation (4):

$$
\mathrm{K}=\frac{9\left(\mathrm{t}_{\mathrm{n}}^{0}\right)^{2}}{2 \mathrm{G}_{\mathrm{Ic}}} .
$$

\section{Results and discussion}

\section{Experimental testing}

\section{Fracture testing}

The typical load-displacement curves of the DCB specimens are shown in Figure 2 and the scatter of the experimental curves is illustrated with a gray error zone. The dashed lines are the results of FEM (see last chapter). The limits of the error zones are calculated by adding or subtracting the standard deviation to an average load value calculated out of four experimental curves at each displacement. Moisture has mainly two effects. First, the maximal load peak is smallest at the highest MC (22\%); second, post-peak behaviors are also different depending on the MC level. Although crack propagation is stable, the dry specimens $(6 \%)$ show the intervals of sudden crack length increment. Such propagation features seldom occur in the specimen with $12 \% \mathrm{MC}$ and are totally absent in samples with $16 \%$ and $22 \% \mathrm{MC}$.

A scheme of the two parts of a specimen after fracture at $22 \% \mathrm{MC}$ is presented in Figure 3 and the scanning electron microscopy (SEM) photograph of the lower part of a fractured specimen. The crack propagates at the interface between wood and the joining material, with frequent crossing to reach the opposite interface. The roughness
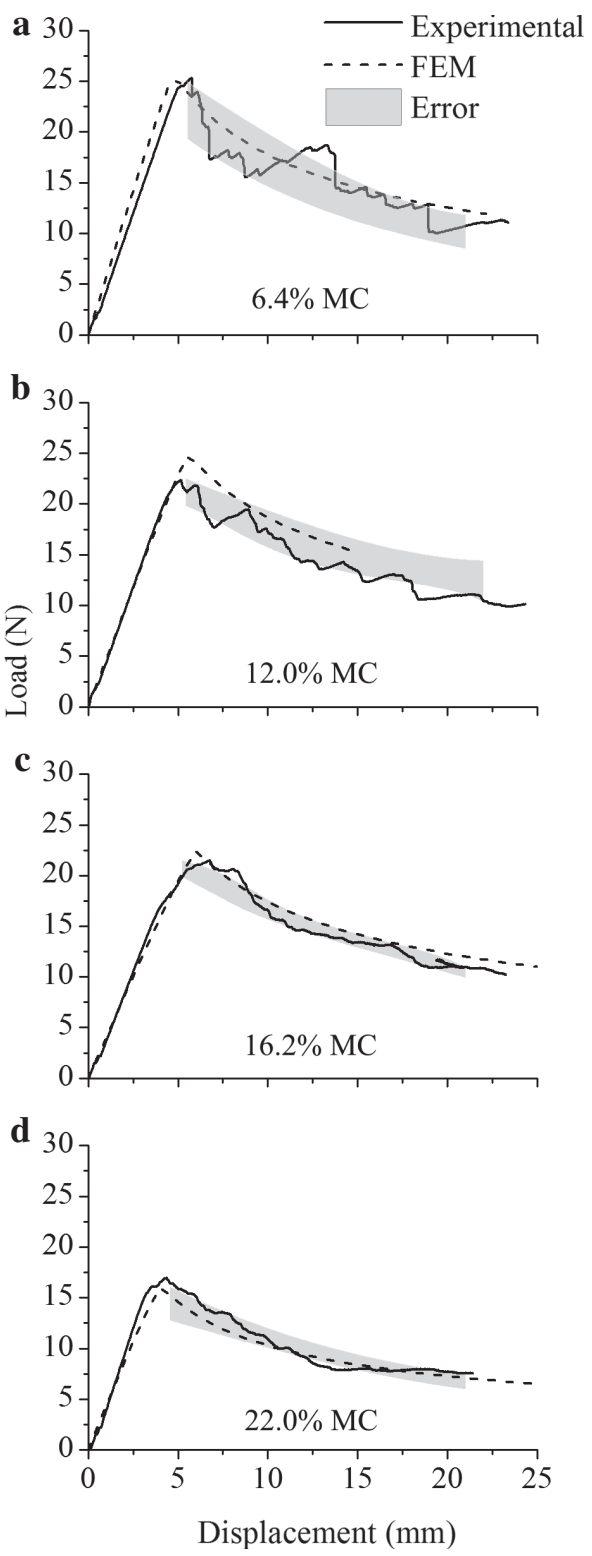

Figure 2 Comparison of typical load-displacement experimental curves (straight lines) with results obtained by FEM (dashed line). The relative error, represented by the gray area, is calculated according to the standard deviation of the experimental data (see text for details).

and fractal analysis of the fractured surfaces do not reveal differences at different MC levels. The photographs of the fracture surfaces for the four levels of MC are displayed in Figure 4, which do not show an effect of MC below $16 \%$. However, at $22 \%$ MC, long wood fibers are visible at the surface of the joining material (Figure 4). In dry conditions, these fibers are embedded in the matrix and break during fracture and only short fiber fragments are elevated above the surface. At higher MC, the fibers are pulled out from the matrix. 


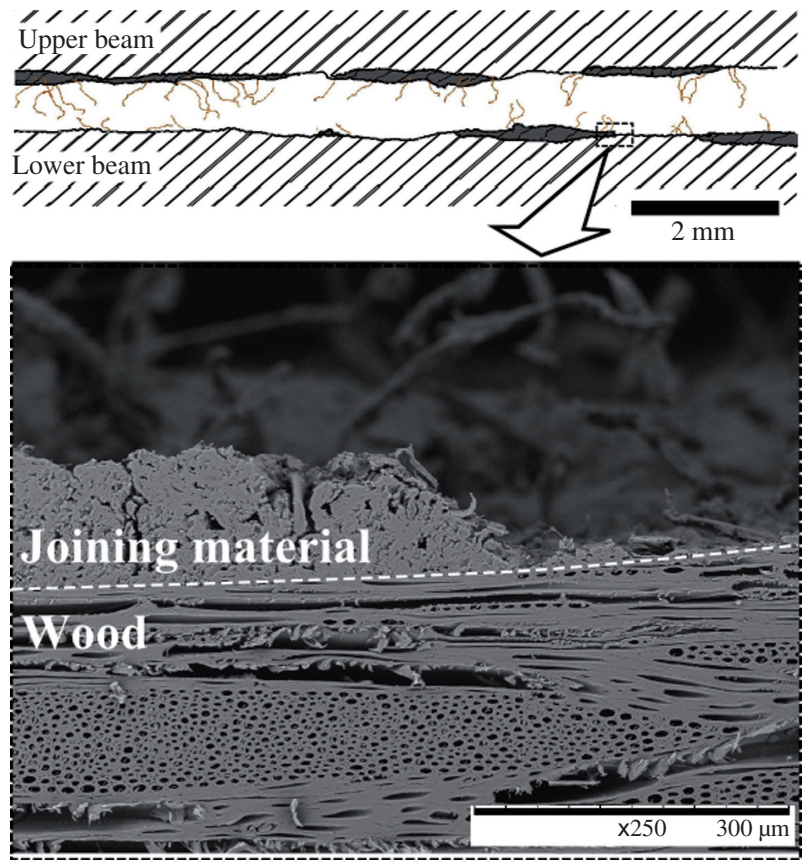

Figure 3 At the top is a schematic representation of the crack path on a moist specimen ( $22 \% \mathrm{MC})$ after separation of the joint. The photograph at the bottom is a magnification of a detail. The SEM picture shows the transition of the crack path that crosses the joint material from one interface to the other.

\section{Energy release rate calculation}

The expression of $\mathrm{G}_{\mathrm{Ic}}$ is given by Equation (5):

$$
\mathrm{G}_{\mathrm{Ic}}=\frac{\mathrm{P}^{2}}{2 \mathrm{~b}} \frac{\partial \mathrm{C}(\mathrm{a})}{\partial \mathrm{a}}
$$

where $\mathrm{P}$ is the value of applied load on the specimen at crack propagation onset, $\mathrm{a}$ is the crack length, $\mathrm{b}$ is for the specimen thickness, and $\mathrm{C}(\mathrm{a})$ is the specimen's compliance in terms of crack length. The measured load $\mathrm{P}$ and the applied displacement enable to calculate the compliance corresponding to the crack length a measured during testing. The values of compliance in terms of a can therefore be fitted with a power equation for subsequent processing:

$$
\mathrm{C}(\mathrm{a})=\mathrm{C}_{1} \mathrm{a}^{\mathrm{m}} \text {. }
$$

Once $\mathrm{C}_{1}$ and $\mathrm{m}$ are determined, the derivative is calculated and inserted in Equation (5) to compute $\mathrm{G}_{\mathrm{Ic}}$.

The points presented in Figure 5 are the average values of $\mathrm{G}_{\mathrm{Ic}}$ calculated in the post-peak region and the error bars are obtained from the standard deviation of the data. Although the results are scattering, no R-curve behavior
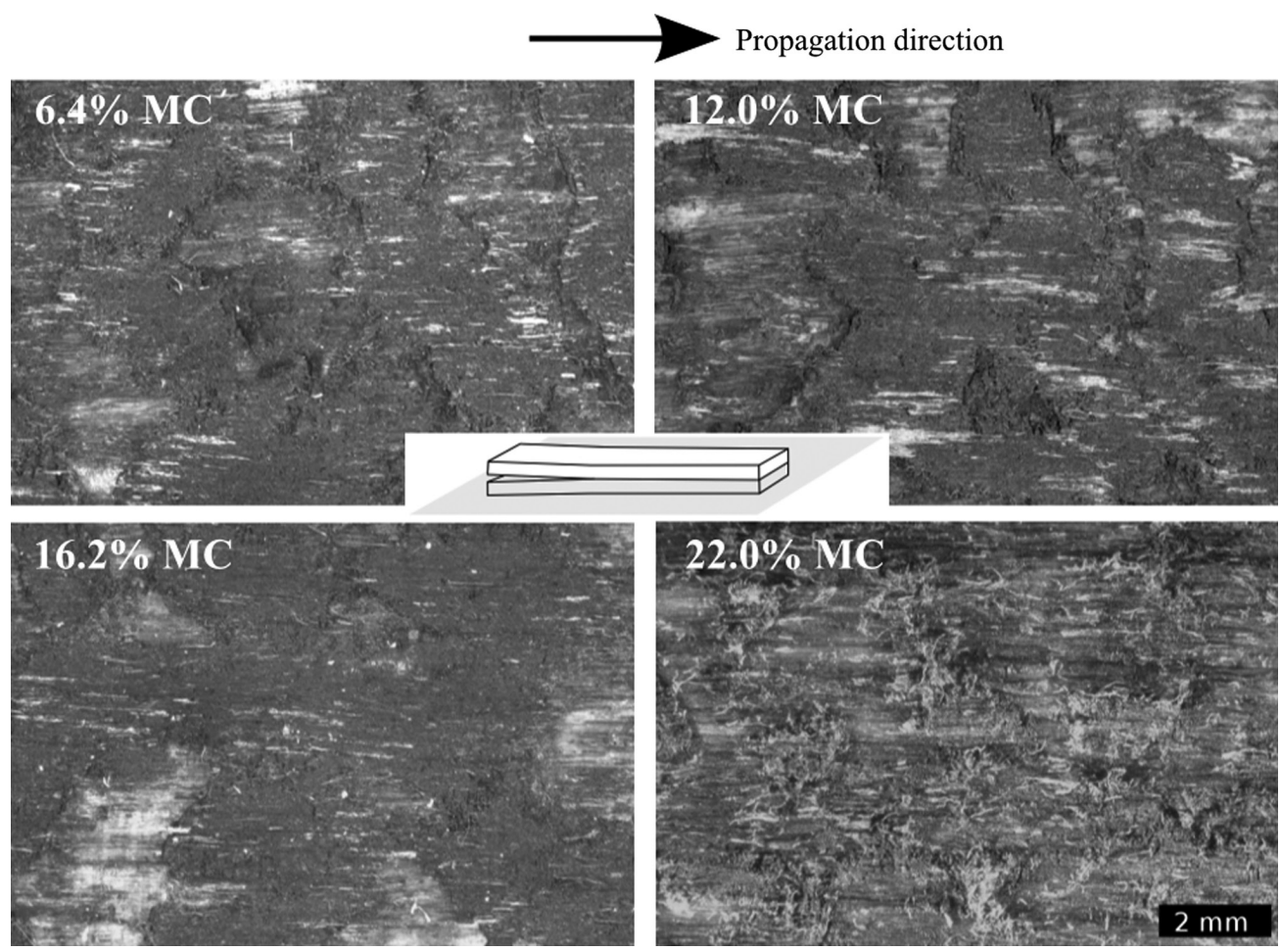

Figure 4 Optical light microscopy photograph of the fracture plans for all four different MC. The fracture surface exhibits features composed of islands and valleys formed by the welded material. The opposite surface has the negative print of these features. At this scale, only the moist specimens exhibits fleecy surface. This is due to long fibers coming out of the joining material. 


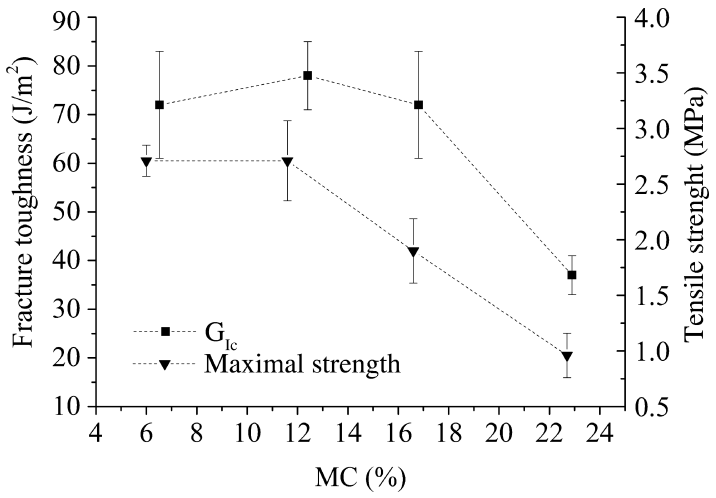

Figure 5 Evolution of the critical energy release rate $\left(\mathrm{G}_{\mathrm{l}}\right)$ and the maximal tensile strength of the welded joint in terms of the corresponding MC.

is seen at any level of MC tested. At the low level of MC, the $G_{\text {Ic }}$ values are quite similar, but a strong decrease at high MC can be noticed. The results are similar to those of Kretschmann and Green (1996), who investigated the $\mathrm{K}_{\mathrm{Ic}}$

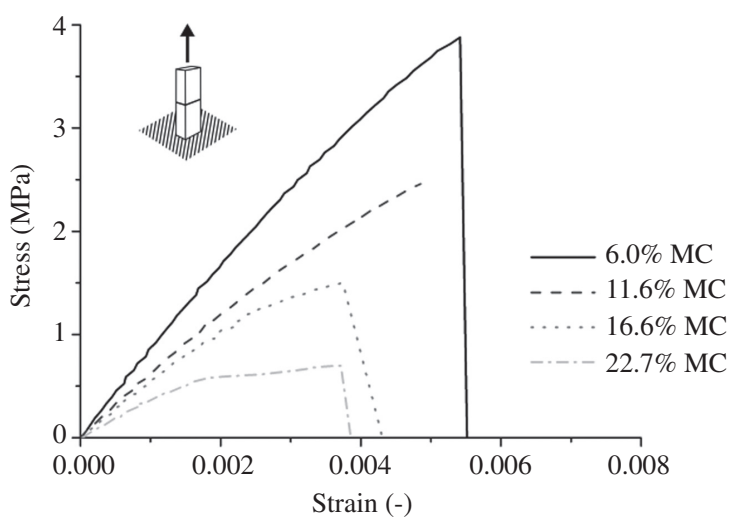

Figure 6 Stress-strain curves obtained during the tensile test at different moisture content. of pine, and the change of fracture properties can be well expressed as a function of MC by a second-order polynomial expression. Based on this, a maximum of $\mathrm{G}_{\mathrm{Ic}}$ should be at $11 \%$ MC.

According to the results of Majano-Majano et al. (2012), the fracture characteristics of a welded wood joint are quite close to those of thermally treated beech. In comparison with the untreated beech, welded joint, independently from the $\mathrm{MC}$, requires about three to four times less energy for the crack to propagate, that is, the joint is the weakest part in a welded wood assembly.

\section{Tensile testing}

The load-displacement curves (Figure 6) obtained from the tensile specimens become more deviating from linearity at higher MC. Fracture always occurs in the joint, which make it possible to calculate its maximal tensile strength. Interestingly, only the high MC specimens demonstrate the discernible damage initiation before fracture, which is characterized by a relatively flat curve. Fibers are well visible in the broken interfaces (Figure 7). The maximal strength values plotted in Figure 5 in terms of MC illustrate that the maximal strength strongly decreases with increasing MC above $12 \%$. Apparently, the moisture also decreases the stiffness as well as the strain to failure (Figure 6).

The EMC calculated for the tensile specimens is slightly different than that of the DCB specimens. This small deviation can be due to the slightly different environmental conditions at the time of weighting the reference specimens. Supposedly, the influence of this has a negligible effect on the elastic constants (Equations (1) and (2)). As a matter of fact, the largest MC difference encountered
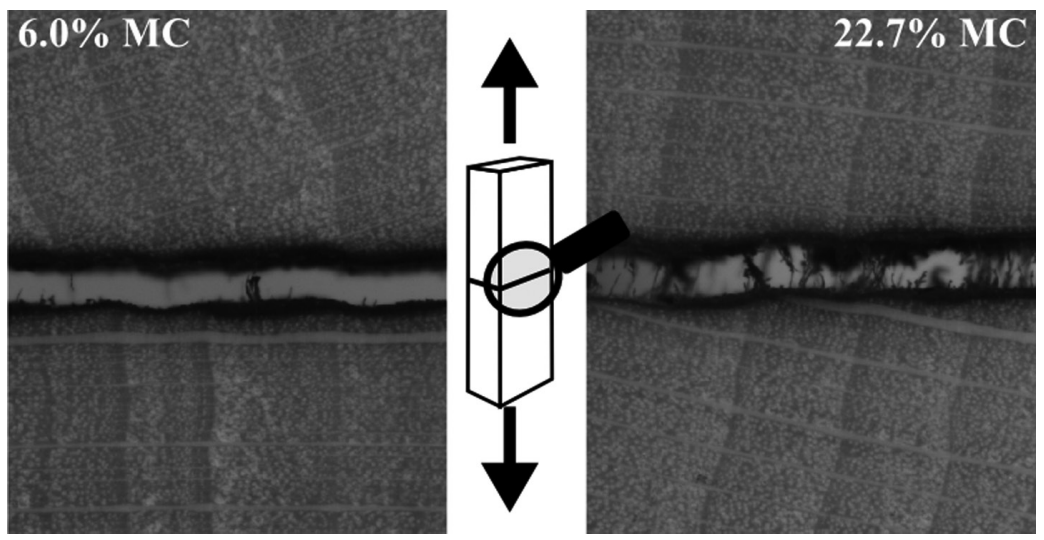

Figure 7 Close images of the fractured joint (black part in the middle) after the tensile test. Fibers entanglement between the two broken parts differentiate the dry (left) and moist (right) specimens. 
$(0.7 \% \mathrm{MC})$ induces a change of $1.3 \%$ on the value of the longitudinal modulus. Therefore, the MCs corresponding to the DCB specimens are used in the calculations.

\section{Finite element modeling}

The maximal strength and critical energy release rate experimentally measured are inserted in the cohesive law presented in Figure 1d. Figure 2 shows the load-displacement curves obtained experimentally and those obtained by FEM (dashed lines). Although the scattering of the experimental curve can reach $15 \%$, the model describes well the observed experimental maximal loads and postpeak behavior. Coureau et al. (2006) and Morel et al. (2010) demonstrated that the presence of fiber bridging during wood fracture requires the use of a bilinear damage law. In the present study, however, a simple linear damage law was sufficient to model the crack propagation during a DCB test. This fact shows that fiber bridging effect has not to be considered, although the optical observations seem to indicate the presence of fibers on the fractured surfaces of the wet specimens (Figures 4 and 7 ).

The decrease of the initial slope on the simulation curves with increasing MC is due to the elastic moduli of wood. The different moduli values decrease with MC according to Equations (1) and (2); therefore, the slope is steeper in the case of elastic loading under dry conditions. The differences in the slopes of the simulated curves and the experimental ones can be explained by the natural variation of the longitudinal modulus of the wood.

\section{Conclusion}

It is possible to determine the critical energy release rate of the joints at different MC with a DCB test. The influence of $\mathrm{MC}$ on the fracture properties is obvious, because the specimens with high $\mathrm{MC}(22 \%)$ have $\mathrm{G}_{\mathrm{Ic}}$ values about half the value of those with low and intermediate MC contents at $6-16 \%$. The optical observations with MC-dependent differences support the influence of moisture. The tensile tests highlight the declining tendency of properties with increasing MC. Fracture toughness and maximal strength show a similar trend at high MC. Accordingly, the loss of fracture toughness is mainly due to the poor performance of the joining material. A FEM representing the DCB test configuration was built based on the experimental data of the DCB and tensile tests. These results show that a linear cohesive law can model well the behavior of welded wood joint under the MC conditions examined in this work.

Acknowledgements: The authors acknowledge the financial support of the Swiss National Science Foundation. SNF Project Nr. CRSI22_127467/1.

Received September 7, 2012; accepted January 15, 2013; previously published online February 23, 2013

\section{References}

Abaqus 6.9 Online Documentation (2009) Dassault System. Conrad, M., Smith, G., Fernlund, G. (2003) Fracture of discontinuous wood-adhesive bonds. Int. J. Adhes. Adhes. 23:39-47.

Coureau, J., Morel, S., Gustafsson, P., Lespine, C. (2006) Influence of the fracture softening behavior of wood on load-COD curve and R-curve. Mater. Struct. 40:97-106.

ASTM (2007) D5528-01. Standard test method for mode I interlaminar fracture toughness of unidirectional fiber-reinforced polymer matrix composites. American Society for Testing Material.

DIN (1977) 52-183. Prüfung von Holz - Bestimmung des Feuchtigkeitsgehaltes.

DIN-EN (2003) 205. Adhesives - wood adhesives for non-structural applications. Determination of the tensile-shear strength of lap joints.

Dinwoodie, J. (1989) Wood, Nature's Cellular, Polymeric FibreComposite. The Institute of Metals, London.

Duchanois, G. (1984) Mesure de la ténacité et étude du comportement mécanique des joints bois-colle. Ph.D. thesis, Institut National Polytechnique de Lorraine.
Dunky, M., Niemz, P. Holzwerkstoffe und Leime - Technologie und Einflussfaktoren. Springer-Verlag, Berlin, 2002.

Frühmann, K., Burgert, I., Stanzl-Tschegg, S.E., Tschegg, E.K. (2003) Mode I fracture behaviour on the growth ring scale and cellular level of spruce (Picea abies [L.] Karst.) and beech (Fagus sylvatica L.) loaded in the TR crack propagation system. Holzforschung 57:653-660.

Gagliano, J.M., Frazier, C.E. (2001) Improvement in the fracture cleavage testing of adhesively-bonded wood. Wood Fiber Sci. 33:377-385.

Ganne-Chédeville, C. (2008) Soudage linéaire du bois: étude et compréhension des modifications physico-chimiques et développement d'une technologie d'assemblage innovante. Ph.D. thesis, Université Henri Poincaré.

Ganne-Chédeville, C., Pizzi, A., Thomas, A., Leban, J., Bocquet, J., Despres, A., Mansouri, H. (2005) Parameter interaction in two-block welding and the wood nail concept in wood dowel welding. J. Adhes. Sci. Technol. 19:1157-1174. 
Ganne-Chédeville, C., Duchanois, G., Pizzi, A., Pichelin, F., Properzi, M., Leban, J. (2008) Wood welded connection: energy release rate measurement. J. Adhes. Sci. Technol. 22:169-179.

Gfeller, B., Zanetti, M., Properzi, M., Pizzi, A., Pichelin, F., Lehmann, M., Delmotte, L. (2003) Wood bonding by vibrational welding. J. Adhes. Sci. Technol. 17:1573-1589.

Gfeller, B., Pizzi, A., Zanetti, M., Properzi, M., Pichelin, F., Lehmann, M., Delmotte, L. (2004) Solid wood joints by in situ welding of structural wood constituents. Holzforschung 58:45-52.

Hering, S., Keunecke, D., Niemz, P. (2012) Moisture-dependent. orthotropic elasticity of beech wood. Wood Sci. Technol. 46:927-936.

Kollmann, F. Technologie des Holzes und der Holzwerkstoffe. Springer-Verlag, Berlin, 1982.

Kretschmann, D.E., Green, D.W. (1996) Modeling moisture contentmechanical properties relationship for clear southern pine. Wood Fiber Sci. 28:320-337.

Landis, E.N., Navi, P. (2009) Modeling crack propagation in wood and wood composites. A review COST Action E35 2004-2008: Wood machining - micromechanics and fracture. Holzforschung 63:150-156.

Liyu, W., Zhenyou, L., Guangjie, Z. (2003) Wood fracture pattern during the water adsorption process. Holzforschung 57: 639-643.

Majano-Majano, A., Hughes, M., Fernandez-Cabo, J.L. (2012) The fracture toughness and properties of thermally modified beech and ash at different moisture contents. Wood Sci. Technol. 46:5-21.

Mansouri, H., Omrani, P., Pizzi, A. (2009) Improving the water resistance of linear vibration-welded wood joints. J. Adhes. Sci. Technol. 23:63-70.

Morel, S., Lespine, C., Coureau, J.-L., Planas, J., Dourado, N. (2010) Bilinear softening parameters and equivalent LEFM R-curve in quasibrittle failure. Int. J. Solids Struct. 47:837-850.

Navi, P., Stanzl-Tschegg, S.E. (2009) Micromechanics of creep and relaxation of wood. A review COST Action E35 2004-2008: Wood machining - micromechanics and fracture. Holzforschung 63:186-195.

Niemz, P. Physik des Holzes und der Holzwerkstoff. DRW-Verlag, 1993.
Omrani, P., Mansouri, H., Duchanois, G., Pizzi, A. (2009) Fracture mechanics of linearly welded wood joints: effect of wood species. and grain orientation. J. Adhes. Sci. Technol. 23:2057-2072.

Pluvinage, G. La Rupture du Bois et de ses Composites. CépaduèsEditions, Toulouse, 1992.

Prokopski, G. (1996) Influence of moisture content on fracture toughness of wood. Int. J. Fracture 79:R73-R77.

Smith, I., Snow, M., Asiz, A., Vasic, S. (2007) Failure mechanisms in wood-based materials: A review of discrete, continuum, and hybrid finite-element representations. Holzforschung 61:352-359.

Qiao, P., Wang, J., Davalos, J. (2003) Tapered beam on elastic. foundation model for compliance rate change of TDCB specimen. Eng. Fract. Mech. 70:339-353.

Rhême, M., Botsis, J., Cugnoni, J., Navi, P. (2013) Influence of the moisture content on the fracture characteristics of welded wood joint. Part 2: mode II fracture. Holzforschung 67:755-761.

Scott, C., River, B., Koutsky, J. (1992) Fracture testing wood adhesive with composite cantilever beam. J. Test. Eval. 21:259-264.

Simon, F. (2001) Endommagement et rupture des joints collés solicitée en traction ou cisaillement. Application au collage du bois. Ph.D. thesis, Université Bordeaux I.

Stamm, B. (2005) Development of friction welding of wood physical, mechanical and chemical studies. Ph.D. thesis, Ecole Polytechnique Fédérale de Lausanne.

Stanzl-Tschegg, S.E., Navi, P. (2009) Fracture behavior of wood and its composites. A review. Holzforschung 63:139-149.

Vasic, S., Stanzl-Tschegg, S. (2007) Experimental and numerical investigation of wood fracture mechanisms at different. humidity levels. Holzforschung 61:367-374.

Vaziri, M., Lindgrend, O., Pizzi, P., Mansouri, H. (2010) Moisture sensitivity of Scots pine joints produced by linear frictional welding. J. Adhes. Sci. Technol. 24:1515-1527.

Wernersson, H. (1991) Fracture characterization of wood adhesive bonds. Paper presented at the 1991 International Timber Engineering Conference, Report TVSM, London.

Yoshihara, H. (2010) Examination of the mode I critical stress intensity factor of wood obtained by single-edge-notched bending test. Holzforschung 64:501-509. 